\title{
Design of Torque Control Strategy for Hybrid Electric Vehicle (HEV) with Maximum Work of Self Commutation Brushless DC Motor using Fuzzy-PI
}

\author{
Yosi Riduas Hais ${ }^{1}$, Mochammad Rameli ${ }^{1}$, Rusdhianto Effendie ${ }^{1}$
}

\begin{abstract}
Hybrid Electric Vehicle (HEV) is vehicle with least two energy sources, such as Internal Combustion Engine (ICE) and Brushless DC Motor (BLDCM). BLDCM provide additional torque, to purpose of $\mathrm{HEV}$ can reach the set point speed according to the reference model. Commutation of BLDCM still complicated, because between the rotational speed of the motor and the speed of the rotary field on the stator should be kept synchronized. Self Commutation used to maintain synchronization between rotation of the rotor and rotary field velocity on BLDCM stator. In addition, this research also applies torque control strategy by using fuzzy-PI controller. Vehicle performance still follows the reference curve with steady state error of $0.1506 \mathrm{~km} / \mathrm{h}$ and $\mathrm{RMSE}$ relative response speed $\mathrm{HEV}$ $<2 \%$.
\end{abstract}

Keywords-HEV, Self Commutation, BLDCM, Fuzzy-PI.

\section{INTRODUCTION}

$\mathrm{HEV}$ is a vehicle with driving force of at least two energy sources [1]. ICE and electric motors are combination of commonly used energy sources [2]. The development of $\mathrm{HEV}$ aims to improve efficiency of fuel consumption, reduction of vehicle exhaust emissions, and improvement of $\mathrm{HEV}$ speed and acceleration response [3]. HEV combines two torque generators, where the prime mover torque is provided by ICE and secondary torque is provided by the BLDCM.

BLDCM is a type of motor developed from DC motor. Development of BLDCM with a purpose to solve commutator brush problems [4]. BLDCM has advantages of high efficiency, large initial torque with smaller physical demands and easier maintenance [5]. However, in terms of setting, BLDCM is still quite complicated because between rotational speed of the motor and the speed of rotary field on the stator shall be kept in sync.

Some research has been done, the method used to synchronize the rotor towards the stator using stator current reading method with $\mathrm{d}-\mathrm{q}$ transformation and compared with actual speed of the rotor. In practice, the method is still

\footnotetext{
${ }^{1}$ Yosi Riduas Hais, Mochammad Rameli, and Rusdhianto Effendie are with Department of Electrical Engineering, Faculty of Electrical Technology, Institut Teknologi Sepuluh Nopember (ITS), Kampus ITS Sukolilo, Surabaya 60111, Indonesia. E-mail: yosiriduashais@gmail.com; rameli@ee.its.ac.id; ditto@ee.its.ac.id.
}

complex and intricate. Another developed method is self commutation.

There are several methods used for BLDCM setting for motor rotation speed and rotational field speed in the stator to remain constant, such as show in Figure 1.

Self Commutation is a method to maintain synchronization between rotation of rotor towards rotary field velocity on stator BLDCM [6]. The circuit topology is also relatively simple and more easily applied to the real plant.

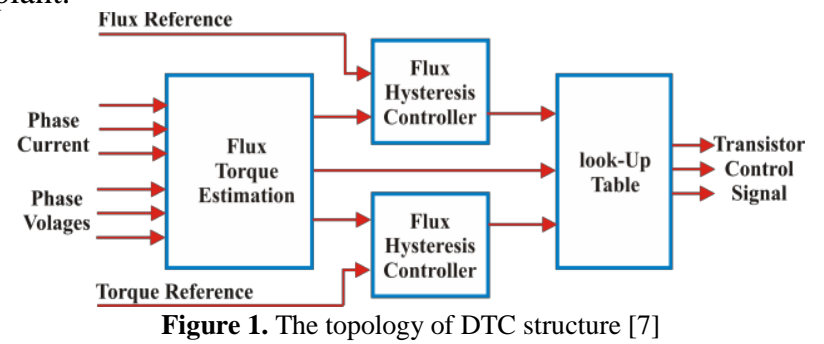

This paper discusses development of self comutation method for BLDCM with torque control strategy by using fuzzy-PI controller for implemented in HEV.

\section{Case Study of Self Commutation BLDCM in HEV}

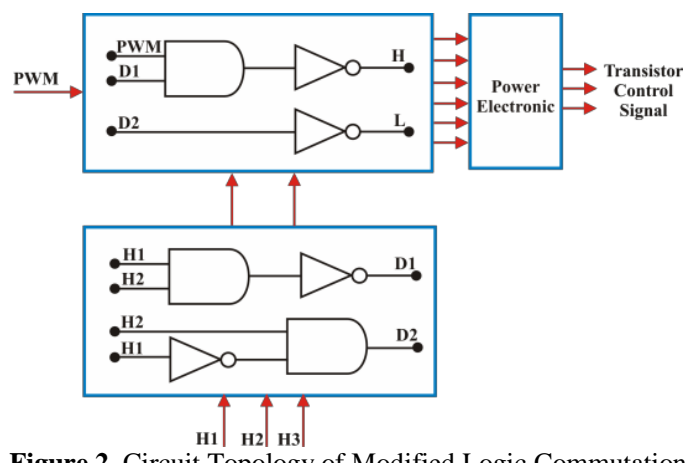

HEV can be divided into three types: series, parallel and power split. [1]. This experiment uses paraller HEV. 


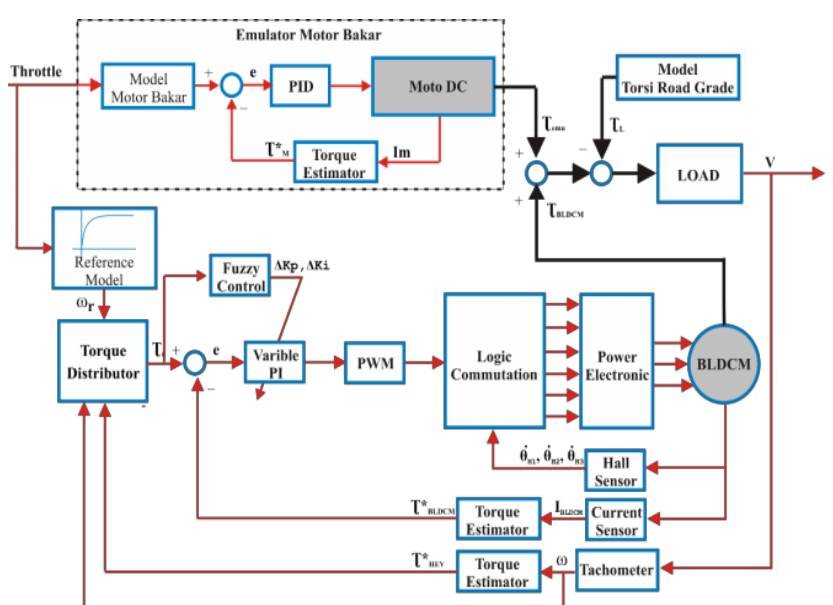

A. Modelling

Identification of ICE parameter is done by using Strejc method based on plot respond of ICE speed. Mathematic model of ICE:

$$
G_{I C E}(s)=\frac{6.0507 \times 10^{-4} s+26.62308 \times 10^{-4}}{0,00896696 s^{2}+0,18938 s+1}
$$

Identification BLDCM parameter is used by analyzing the result of measurement (Table 1).

\begin{tabular}{ll}
\multicolumn{2}{c}{ TABLE 1. } \\
\hline \hline ParameTER OF BLDCM \\
\hline Pole (P) & Mark \\
Voltage Source (Volt) & 48 \\
Stator resintace (Ohm) & 0,85 \\
Stator inductance (H) & 0,0142 \\
Mutual inductance (H) & 0,0136 \\
Constant of torque (Nm/A) & 0,366 \\
Constan of back emf (V/rad) & 0,09 \\
\hline \hline
\end{tabular}

Mathematic model of load:

$$
G_{L}(s)=\frac{1}{3 \times 10^{-4} s+13.2 \times 10^{-4}}
$$

Reference model is a guide model for controller to increase HEV respond. Mathematic model of model reference:

$$
G(s)=\frac{2.0169}{0.104 s+1}
$$

BLDCM Stator current equation:

$$
\frac{d}{d t}\left[\begin{array}{l}
i_{U} \\
i_{V} \\
i_{W}
\end{array}\right]=D^{-1}\left\{R I\left[\begin{array}{l}
i_{U} \\
i_{V} \\
i_{W}
\end{array}\right]+I\left[\begin{array}{c}
i_{U} \\
i_{V} \\
i_{W}
\end{array}\right]-I\left[\begin{array}{l}
i_{U} \\
i_{V} \\
i_{W}
\end{array}\right]\right\}
$$

\section{B. Design Fuzzy-PI Controller}

Torque control of BLDCM done by setting the BLDCM torque directly. At this phase designed fuzzy-PI controller. PI controller designed to set BLDCM torque. The PI Controller equation is given in the equation 3 . The parameter PI obtained tuning with MATLAB.

$$
u(t)=K_{p} e(t)+K_{i} \int_{0}^{t} e(t) d t
$$

$$
e(t)=T_{\text {refBLDCM }}(t)-T_{\text {estBLDCM }}
$$

Where the torque of BLDCM estimates is

$$
T_{\text {estBLDCM }}(t)=I_{M}(t) K_{T M}(t)
$$

The BLDCM currents are obtained from the equation (8)

$$
I_{M}=\frac{a b s\left(I_{U}+I_{V}+I_{W}\right)}{2}
$$

Which is the value of $\mathrm{Kp}$ and $\mathrm{Ki}$ always updated with equation (9) and (10).

$$
\begin{aligned}
& K_{p}=K^{\prime}{ }_{p}+\Delta K_{p} \\
& K_{i}=K^{\prime}{ }_{i}+\Delta K_{i}
\end{aligned}
$$

$K^{\prime}{ }_{p}$ is the gain of $K_{p}$ and $K_{i}^{\prime}$ is gain of Ki before time t.

The rules tuner $\mathrm{Kp}$ are defined according to the following

\begin{tabular}{|c|c|c|c|c|}
\hline \multirow{5}{*}{ 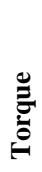 } & \multicolumn{4}{|c|}{ 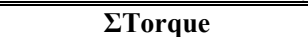 } \\
\hline & & $\mathbf{N}$ & O & $\mathbf{P}$ \\
\hline & $\mathbf{N}$ & Max & Max & Nom \\
\hline & O & Max & Nom & Min \\
\hline & $\mathbf{P}$ & Nom & Min & Min \\
\hline
\end{tabular}
algorithm:

$$
\begin{aligned}
& \text { If } T=K, \text { then } \Delta K_{p} \text { is Min } \\
& \text { If } T=B, \text { then } \Delta K_{p} \text { is Max } \\
& \text { If } T=\text { Nol, then } \Delta K_{p} \text { is Nom }
\end{aligned}
$$

The rules tuner $\mathrm{Ki}$ are defined according to the following algorithm which has shown in Table 2.

TABLE 2.

RULES BASE OF FUZZY TUNER $K_{i}$

\section{RESULT AND DISCUSSION}

HEV simulation and modeling is made with Matlab Simulink. Here are the test results:

\section{A. Acceleration Testing of HEV}

\section{1) HEV Testing with External Torque Disturbance}

Testing this stage is done by providing an external load of $0.08 \mathrm{~N}$.m which is assumed as slope of the road, then getting fuzzy control strategy applied. Gain speed regulator is given with value of $\mathrm{Kp}=5, \mathrm{Ki}=1.5$, The speed response (Figure 4) indicates the steady state speed value of 60 $\mathrm{Km} / \mathrm{h}$. When given a load at time of $0.8 \mathrm{~s}$, HEV can still maintain speed as per reference.

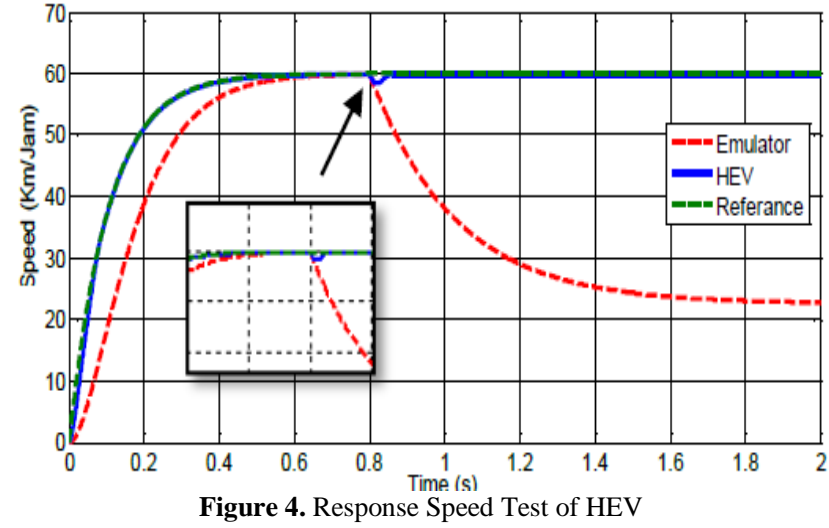

Figure 5 represents steady state error value of 1,566 Km/h and RRMSE of $<2 \%$ for application of fuzzy control strategy. 
The $3^{\text {rd }}$ International Seminar on Science and Technology

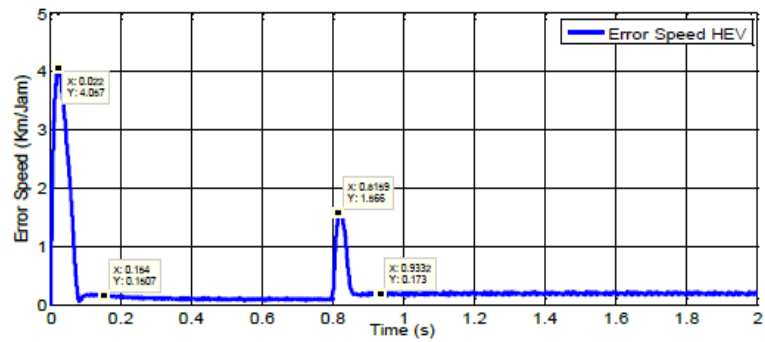

Figure 5. Response Error Speed Test of HEV

HEV torque response (Figure 6) points out torque ripple with steady state value of $0.1422 \mathrm{~N}$.m before the load is applied. At the time of $0.8 \mathrm{~s}$, torque value is changed due to given load and average torque value of HEV 0.1444 N.m. HEV torque is a combined torque of ICE and BLDCM torque, thus the value is greater.

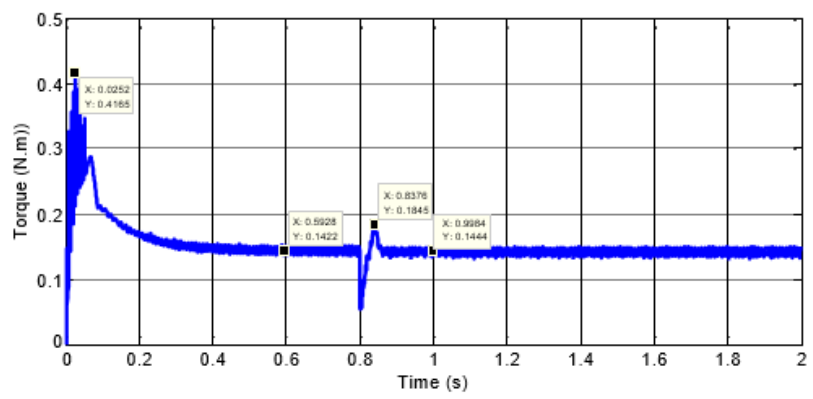

Figure 6. Response Torque of HEV

TABLE 3.

TEST RESUlt

\begin{tabular}{cccc}
\hline \hline $\begin{array}{c}\text { Disturbance } \\
\mathbf{( N . m )}\end{array}$ & $\begin{array}{c}\text { Speed } \\
\mathbf{( k m} / \mathbf{h})\end{array}$ & $\begin{array}{c}\text { Average Error } \\
\mathbf{( k m} / \mathbf{j a m})\end{array}$ & $\begin{array}{c}\text { RRMSE } \\
\mathbf{( \% )}\end{array}$ \\
\hline 0 & 59,9086 & 0,1938 & 0,932 \\
0,07 & 59,8445 & 0,2488 & 0,968 \\
0,08 & 59,8385 & 0,2595 & 0,983 \\
0,09 & 59,8189 & 0,2719 & 1,004
\end{tabular}

\begin{tabular}{llll}
0,1 & 59,7974 & 0,2848 & 1,027 \\
\hline \hline
\end{tabular}

\section{CONCLUSION}

The results showed that Self Commutation method can synchronize well rotation speed of the rotor towards speed of rotary field on the stator. The self commutation BLDCM scheme can be applied to HEV. Vehicle performance still follows the reference curve with steady state error value $0.1506 \mathrm{~km} / \mathrm{h}$ and RRMSE response speed $<2 \%$ when the control strategy applied in HEV.

\section{REFERENCES}

[1] C. Mi, M. A. Masrur, and D. W. Gao, Hybrid Electric Vehicles. Chichester, UK: John Wiley \& Sons, Ltd, 2011.

[2] F. U. Syed, M. L. Kuang, M. Smith, S. Okubo, and Hao Ying, "Fuzzy Gain-Scheduling Proportional-Integral Control for Improving Engine Power and Speed Behavior in a Hybrid Electric Vehicle,” IEEE Trans. Veh. Technol., vol. 58, no. 1, pp. 69-84, Jan. 2009.

[3] Y. Zhang, X. Yu, M. Bi, and S. Xu, "An adaptive neural PID controller for torque control of hybrid electric vehicle," in 2011 6th International Conference on Computer Science \& Education (ICCSE), 2011, pp. 901-903.

[4] C.-Y. Chen, W.-C. Chan, T.-C. Ou, S.-H. Yu, and T.-W. Liu, "Sliding mode speed control of Brushless DC Motor using PulseWidth-Modulated current regulator," in 2009 IEEE/ASME International Conference on Advanced Intelligent Mechatronics, 2009, pp. 1395-1399.

[5] B. K. Lee and M. Ehsani, "Advanced BLDC motor drive for low cost and high performance propulsion system in electric and hybrid vehicles," in IEMDC 2001. IEEE International Electric Machines and Drives Conference (Cat. No.01EX485), pp. 246-251.

[6] Fahrul, "Perancangan Konstruksi Self Commutation Multistage Axial Field Bldc Motor Dengan Pengaturan Kecepatan Menggunakan Sliding Mode Control (SMC),” Institut Teknologi Sepuluh Nopember.

[7] M. Kazmierkowski, L. Franquelo, J. Rodriguez, M. Perez, and J. Leon, "High-Performance Motor Drives," IEEE Ind. Electron. Mag., vol. 5, no. 3, pp. 6-26, Sep. 2011. 